\title{
Lawrence Livermore National Laboratory Summer Employment Summary
}

\author{
A.J. Wilson
}

August 6, 2002

U.S. Department of Energy

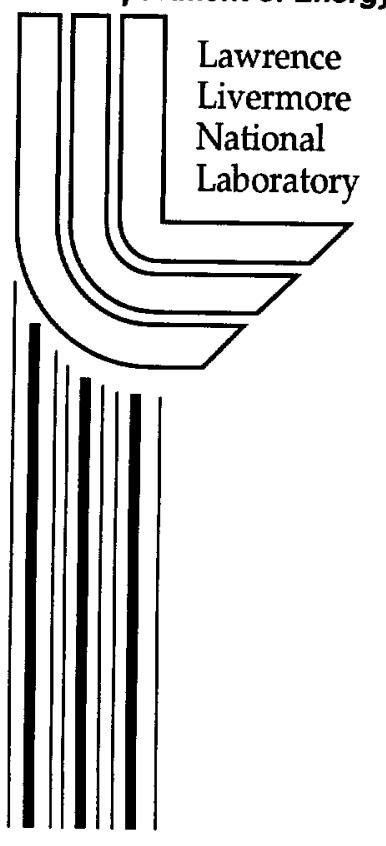




\section{DISCLAIMER}

This document was prepared as an account of work sponsored by an agency of the United States Government. Neither the United States Government nor the University of California nor any of their employees, makes any warranty, express or implied, or assumes any legal liability or responsibility for the accuracy, completeness, or usefulness of any information, apparatus, product, or process disclosed, or represents that its use would not infringe privately owned rights. Reference herein to any specific commercial product, process, or service by trade name, trademark, manufacturer, or otherwise, does not necessarily constitute or imply its endorsement, recommendation, or favoring by the United States Government or the University of California. The views and opinions of authors expressed herein do not necessarily state or reflect those of the United States Government or the University of California, and shall not be used for advertising or product endorsement purposes.

This work was performed under the auspices of the U.S. Department of Energy by the University of California, Lawrence Livermore National Laboratory under Contract No. W-7405-Eng-48.

This report has been reproduced directly from the best available copy.

Available electronically at http://www.doc.gov/bridge

Available for a processing fee to U.S. Department of Energy

And its contractors in paper from

U.S. Department of Energy

Office of Scientific and Technical Information

P.O. Box 62

Oak Ridge, TN 37831-0062

Telephone: (865) 576-8401

Facsimile: (865) 576-5728

E-mail: reports@adonis.osti.gov

Available for the sale to the public from

U.S. Department of Commerce

National Technical Information Service

5285 Port Royal Road

Springfield, VA 22161

Telephone: (800) 553-6847

Facsimile: (703) 605-6900

E-mail: orders@ntis.fedworld.gov

Online ordering: http://www.ntis.gov/ordering.htm

OR

Lawrence Livermore National Laboratory

Technical Information Department's Digital Library

http://www.llnl.gov/tid/Library.html 


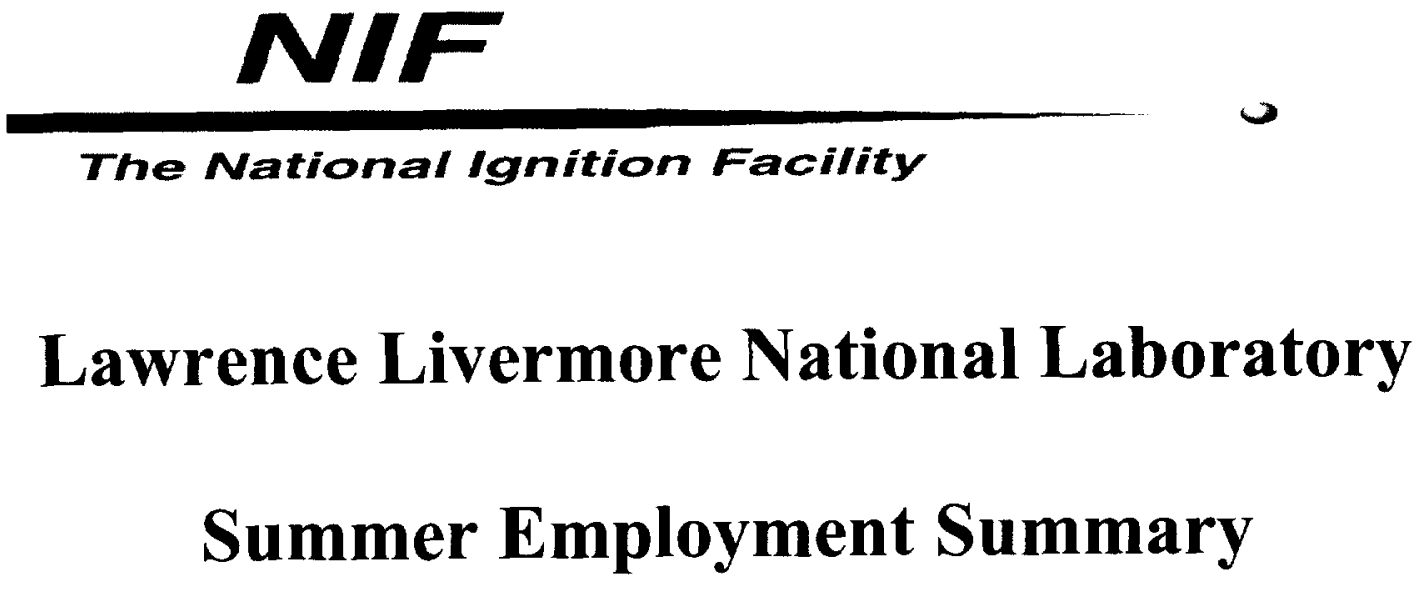

Anthony J. Wilson 


\section{CONTENTS}

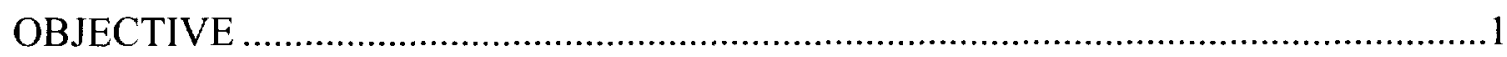

EMPLOYMENT INFORMATION ...................................................................

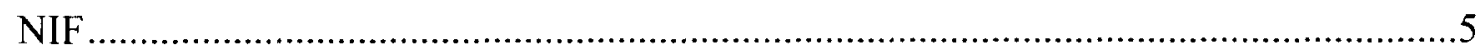

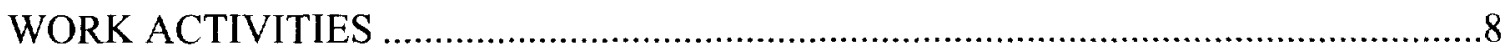

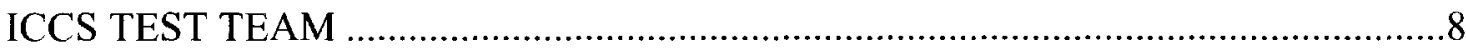

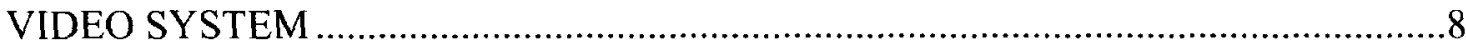

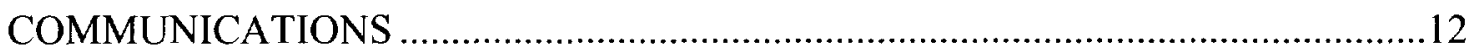

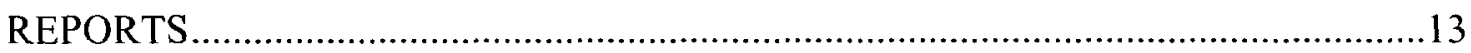

COLLEGE COURSE/WORK ENHANCEMENT .................................................. 19

IMPACT OF PREVIOUS COURSES ON WORK ASSIGNMENT ........................19

IMPACT OF WORK ASSIGNMENT ON FUTURE COURSES...............................19

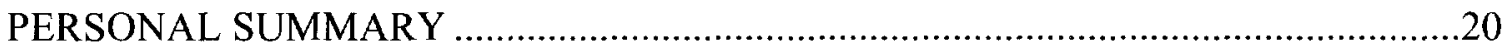




\section{OBJECTIVE}

This document will serve as a summary of my work activities as a summer employee for the Lawrence Livermore National Laboratory (LLNL). The intent of this document is to provide an overview of the National Ignition Facility (NIF) project, to explain the role of the department that I am working for, and to discuss my specific assigned tasks and their impact on the NIF project as a whole.

LLNL Summer Employment Summary

Page 1 of 21 


\section{EMPLOYMENT INFORMATION}

Resources of the University of California system operate the Lawrence Livermore National Laboratory for the U.S. Department of Energy. The laboratory is an applied science U.S. national security laboratory. It serves as a resource for the U.S. Government and a partner with commercial industry and academia. The main site is located in Livermore, California, just 50 miles east of San Francisco. There is another smaller laboratory site, named Site 300 , which is located between Livermore and Tracy, California. This site is used primarily for explosive detonation testing. LLNL employs roughly 8,000 employees. The LLNL organization structure is divided into 12 directorates. Directorates can be thought of as separate operating divisions similar to those of private sector corporations. Currently, I am working under the NIF Directorate for the Integrated Computer Control System (ICCS) Test Team. Figures 1 and 2 below show the organization charts of the ICCS organization and the NIF ICCS Test Team: 


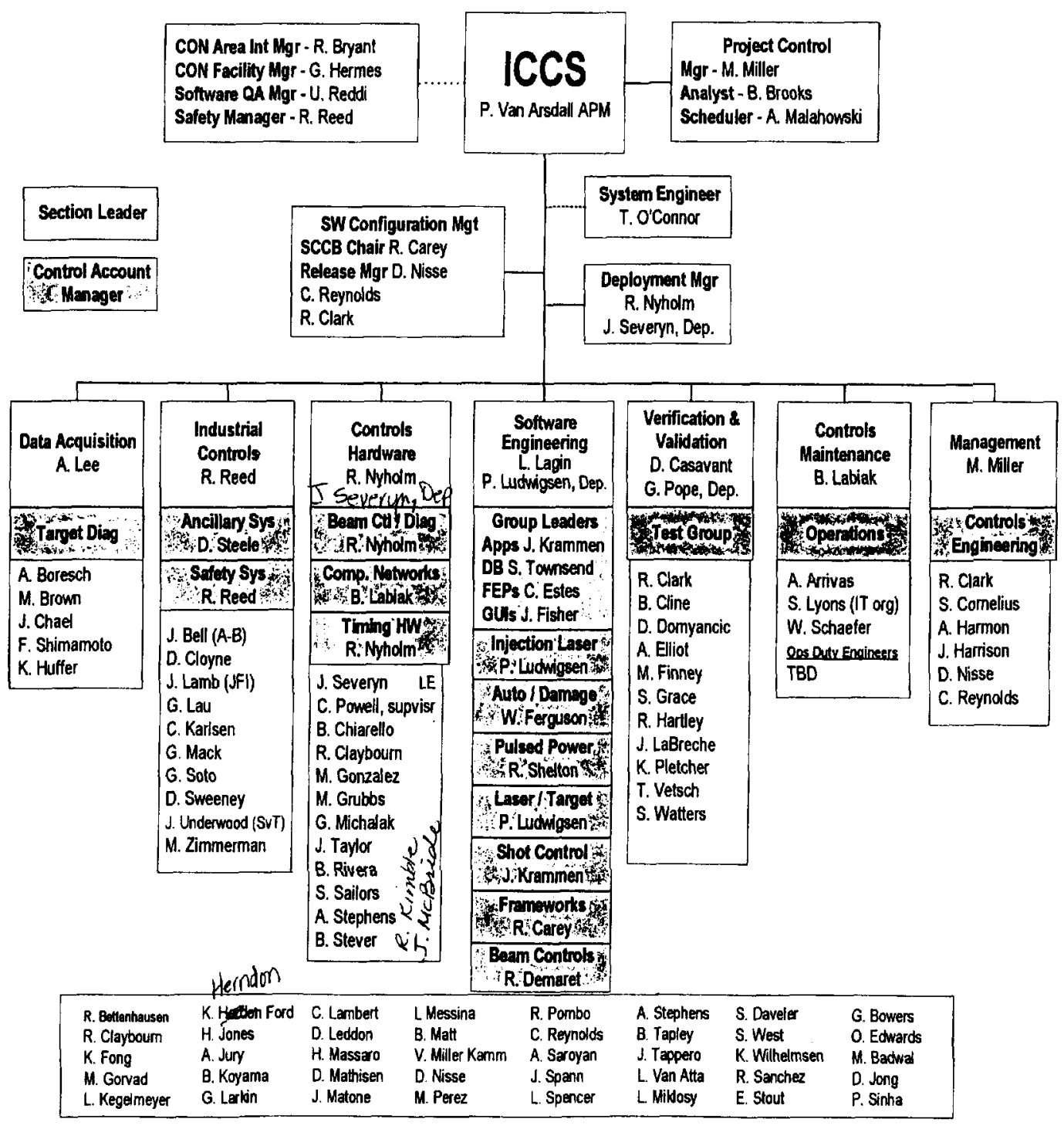

Figure 1: ICCS Organization

LLNL

Summer Employment Summary

Page 3 of 21 


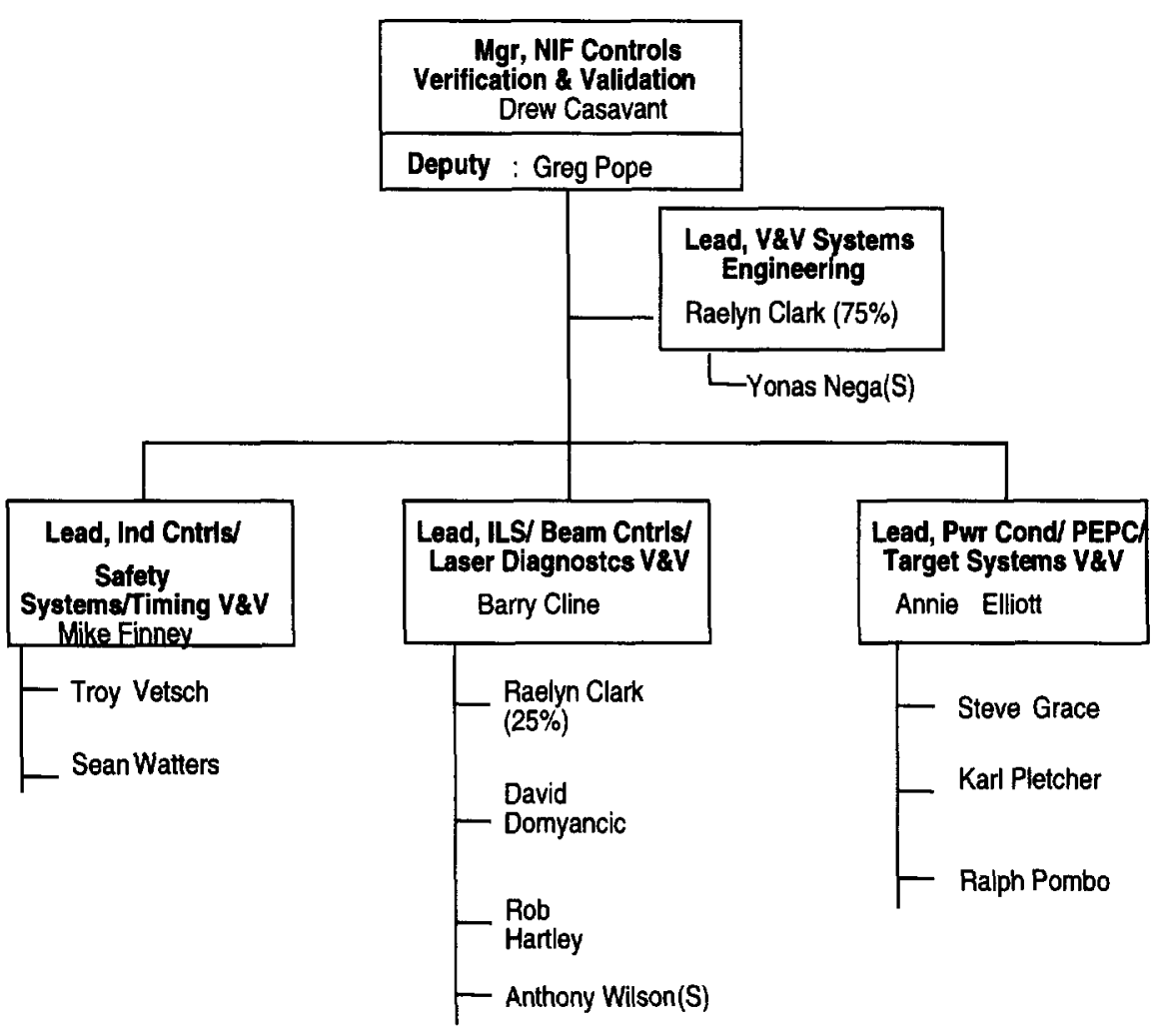

Figure 2: NIF ICCS Test Team

LLNL 


\section{NIF}

The NIF will house the world's largest and most powerful experimental laser. The project is under development for the U.S. Department of Energy's Nuclear Security Administration Defense program. The primary missions of the NIF project are to provide our nation with a means of effective and reliable nuclear testing, to provide a means to attain fusion ignition in the laboratory to explore fusion as a potential future energy source, and to provide a means to further explore astrophysics, space physics, hydrodynamics, plasma physics, and other science areas. LLNL was selected as the site for this project because of the laboratory's mission of ensuring that our nation's nuclear weapons remain safe, secure, and reliable.

After the laser is completely assembled, it will utilize 192 beams that will produce 1.8 million joules (about 500 trillion watts of power) of laser light for about 20 billionths of a second. The NIF will focus its 192 laser beams onto a BB-sized capsule of deuterium and tritium fuel, forcing the two heavy isotopes of hydrogen to combine through compression and heating to 50 million degrees producing ignition and a self-sustaining fusion reaction.

The NIF laser is housed in a facility measuring more than two football fields in length. An aerial photo of the NIF building is provided in Figure 3, and a 3D model of the facility showing the various NIF laser components is shown in Figure 4. The target chamber, which measures 10 meters in diameter, provides state-of-the-art x-ray and neutron diagnostics capability for a wide range of experimental uses. 


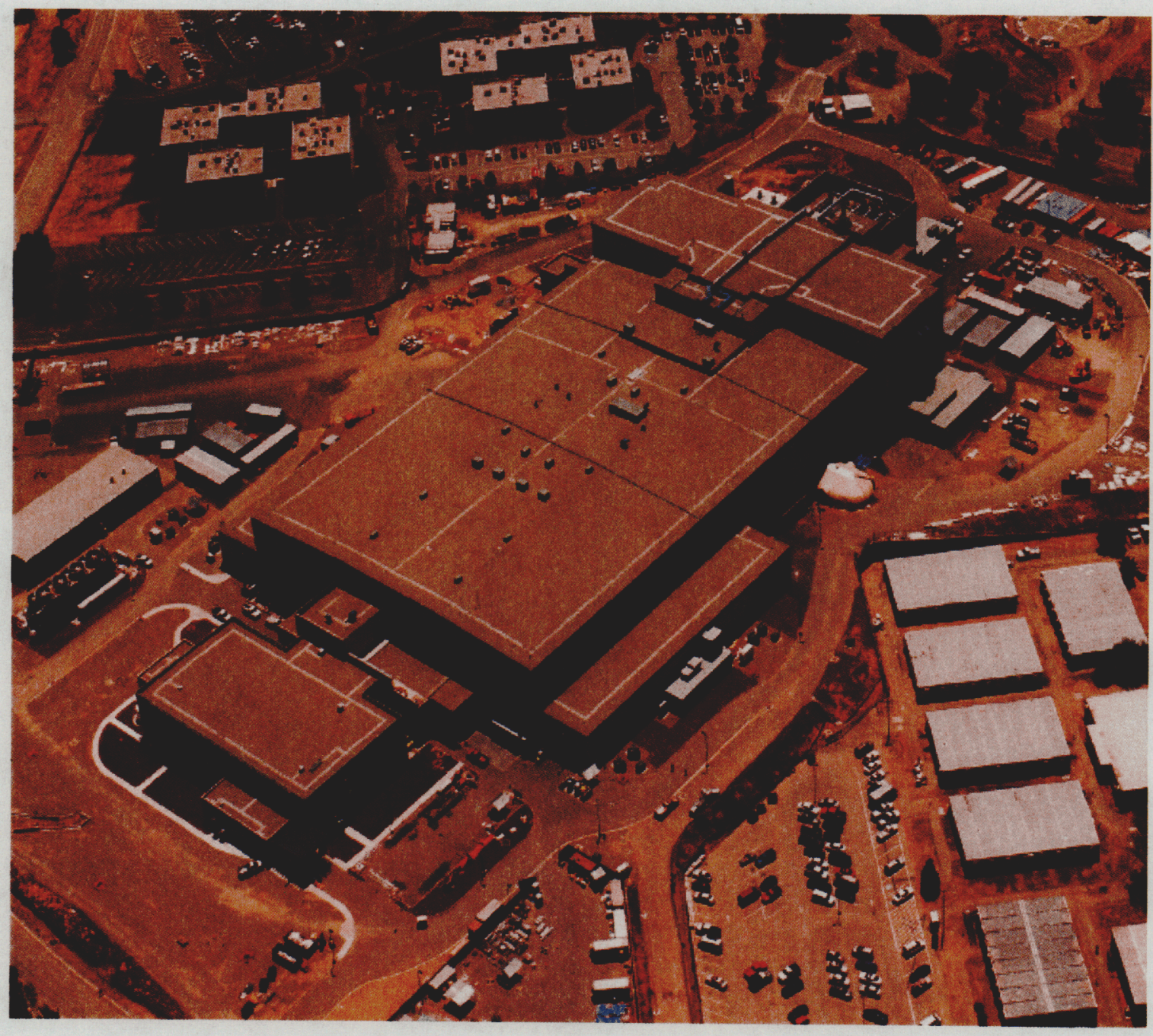

Figure 3: NIF Building 581

LLNL 


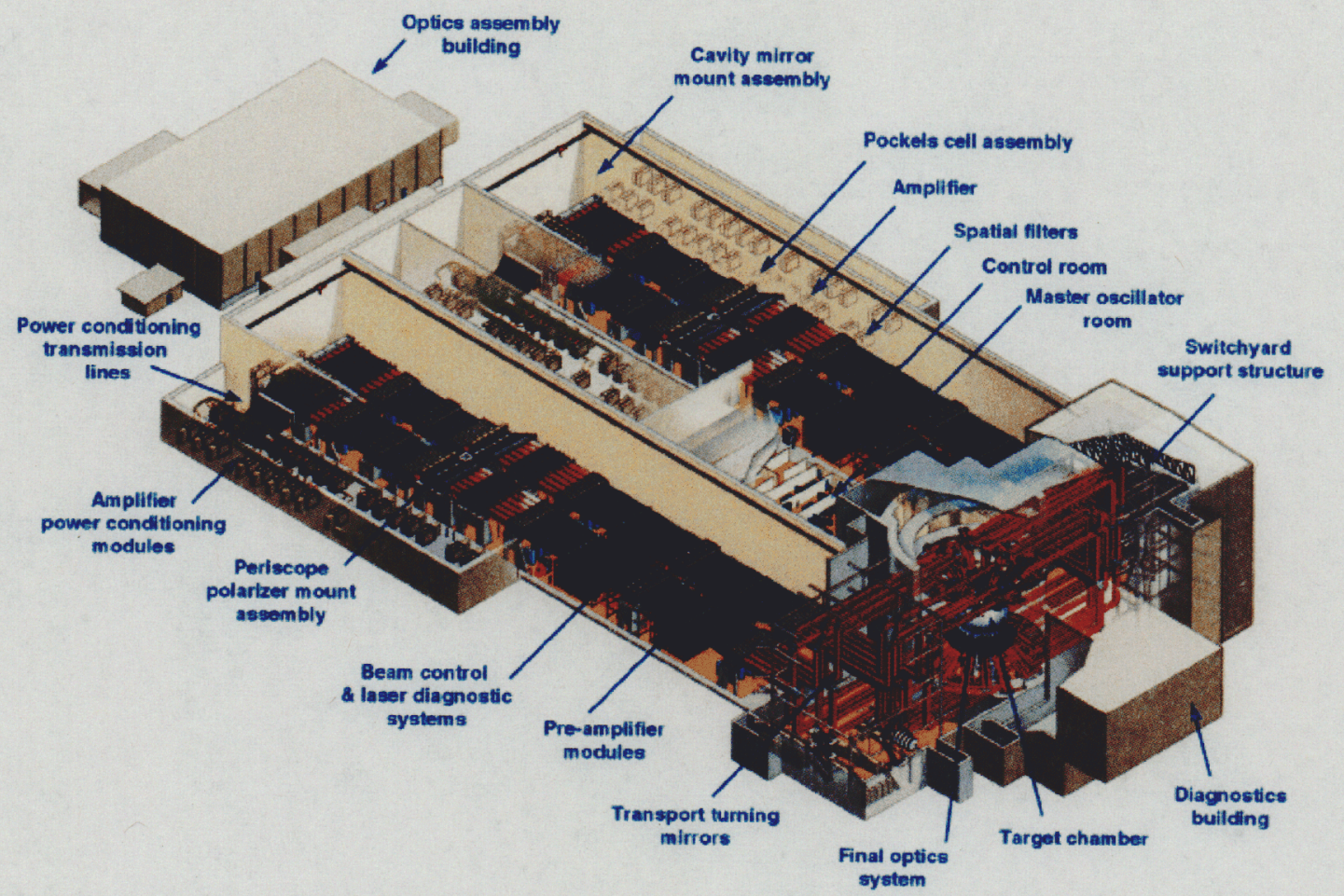

Figure 4: NIF 3D Model

LLNL 


\section{WORK ACTIVITIES}

\section{ICCS CONTROLS TEST TEAM}

The ICCS Controls Test Team is primarily responsible for evaluating software quality and performing control system acceptance tests for NIF. By performing these acceptance tests the control system is validated, which ensures that it meets the needs of NIF Operations. The Controls Test Team is also responsible for comparing the content of individual software releases with pre-release goals to help the project assess the viability of software development schedules.

The test team utilizes a "Test Bed" located in B490 as a software/hardware integration lab. By utilizing hardware and software emulators, testers can perform preliminary testing of released software, functional testing of hardware components, and specialized testing for resolving system defects that may be observed in NIF. The B490 Test Bed is also available for software developers to conduct unit testing of software modules.

\section{VIDEO SYSTEM}

One of my assignments for the summer has been to exercise a test matrix for the NIF ICCS Video System software to verify that the software meets its functional requirements, its performance requirements, and the intended interface requirements. A simple block diagram of the Video System is shown in Figure 5. As seen from the diagram, the user interfaces with the system by means of a graphical user interface (GUI), running on a Sun Microsystems workstation. The Sun workstation is connected to the Video Front End Processor (VFEP) over Ethernet or an Asynchronous Transfer Mode (ATM) network. 
The VFEP is the computer system and software component that acquires video images and transmits them over the computer network to a client system. Each VFEP contains Frame Grabber cards that digitize video images received from up to 4 cameras. When completed, the NIF will contain approximately 500 VFEPs with up to 12,000 cameras.

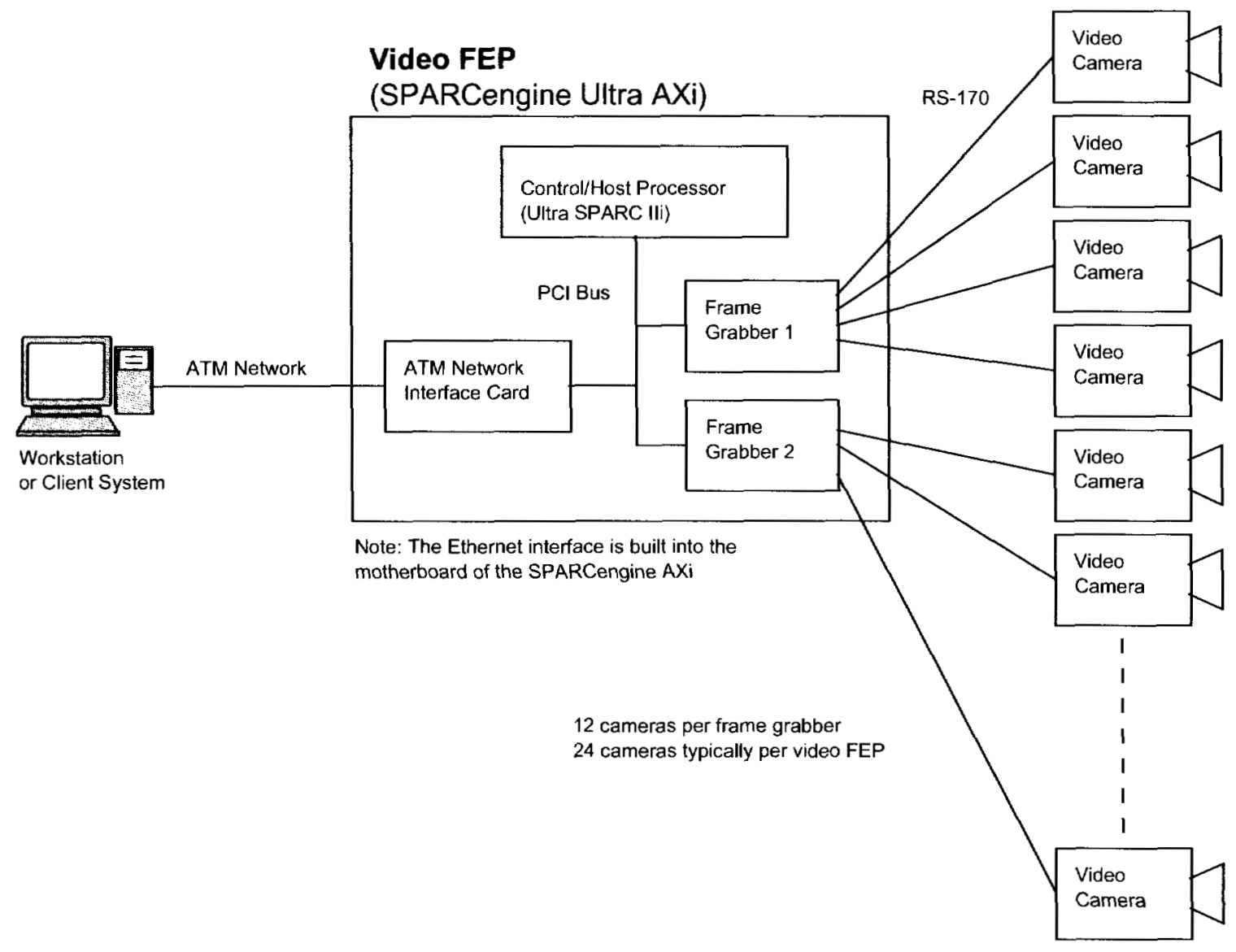

Figure 5: Video System Block Diagram 
Some of the VFEP performance requirements are:

Start-Up - The VFEP must know how to boot itself, recognize the network, and execute start-up software. It must configure its software correctly for the particular video cameras (device objects) and frame grabbers (controller objects) associated with that FEP.

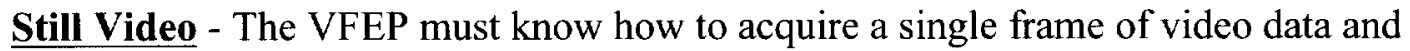
transmit it to a client system upon command.

Motion Video - The VFEP must know how to acquire a motion video stream and transmit it to a client system upon command.

Triggered Still Video - The VFEP must know how to acquire a single frame of video data synchronized to a trigger from the Integrated Timing System and transmit it to a client system upon command.

Triggered Motion Video - The VFEP must know how to acquire a motion video stream with each frame synchronized to a trigger from the Integrated Timing System and transmit it to a client system upon command.

Shot Capture - The VFEP must know how to acquire a single frame of video data synchronized with a laser shot.

Shut Down - The FEP must know how to disconnect itself from ICCS and to gracefully shut down its software and hardware components. 
The Video GUI is the client software component that constructs and sends video acquisition commands to specific VFEPs. The Video GUI also receives and displays the video image transmitted from the VFEPs. Some of the Video GUI performance requirements are:

Start-Up - The Video GUI must know how to start itself and recognize the network.

Request and Display Still Image - The Video GUI must know how to request and display a still image received from a chosen camera, both for still image display and shot capture.

Request and Display Motion Video - The Video GUI must know how to request and display a motion video image stream received from a chosen camera.

Store Image Data - The Video GUI must know how to send a chosen image or image stream to local archival storage.

Shut-Down - The Video GUI must know how to disconnect itself from ICCS and to gracefully shut itself down.

The Video System plays a major role between the other components of the ICCS software. There are other ICCS components that depend on the VFEPs to perform their individual tasks correctly and precisely. These system components are: Alignment Controls, Laser Diagnostics, Target Diagnostics, and Automatic Alignment. A block diagram of the ICCS subsystems and other Application FEPs are shown in Figure 6.

LLNL Summer Employment Summary

Page 11 of 21 


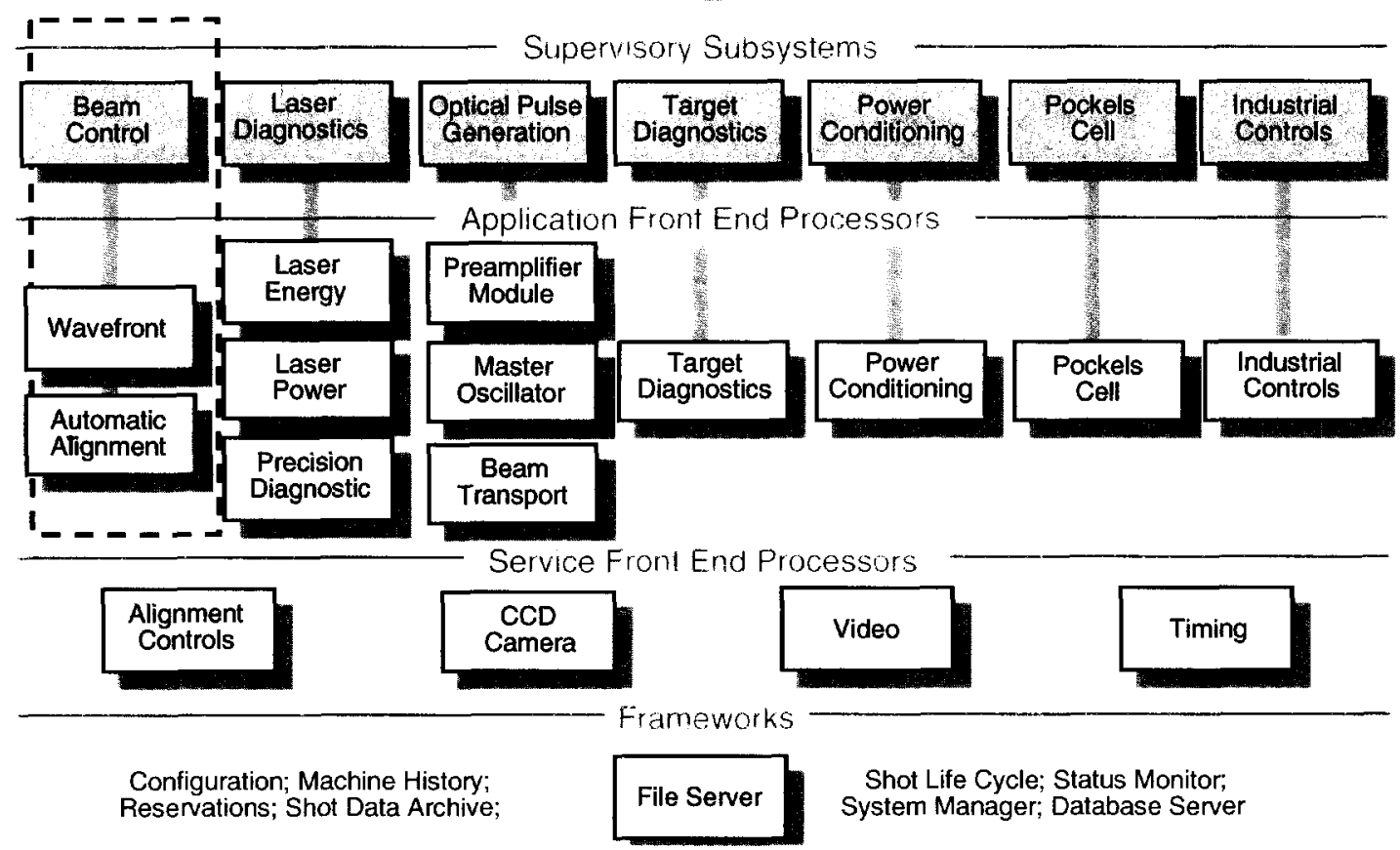

Figure 6: Layered ICCS

\section{COMMUNICATIONS}

Daily test activities in B581 are considered to be "Online Testing". The term online is used to indicate that there will be NIF control system hardware and software that is activated. All activities must first be coordinated with the NIF Control Room Facility Manager (FAM) and the ICCS Controls Activation Manager (CAM) in advance of any work activity or use of any portion of the NIF ICCS. Daily commissioning meetings are held to plan the commissioning activities and to discuss any possible hazards along with the controls for the hazards. Each participant must attend this meeting to review and sign the daily Safe Plan of Action (SPA). 
The ICCS Controls Test Team will usually hold a general team meeting at the beginning of each month. The goals of these meetings are to discuss the overall direction of the NIF project and to discuss the Controls Test Team's direction. A discussion of individual team member's priorities will also take place at this time.

\section{REPORTS}

Preparing a monthly status report and a test results Quick Look Report (QRL) are two methods of documenting and informing others of individual activities. The monthly status report is used to keep management informed of individual progress on assigned tasks and other activities. As testing activities are concluded, the tester should prepare a QRL that summarizes the test activities. Below I have included my status reports for May 2002 through July 2002, and a QRL for my activities that covered NIF Early Light (NEL) 1.0 testing for the Video System software. 


\section{Monthly Status - May 2002}

\section{Anthony J. Wilson}

\section{Accomplishments}

- Office Logistics

1. Setup PC to gain access to the network, e-mail, PH system, Lite System, etc.

2. Computer Accounts - NIF Program Server, UNIX, Database, SCRTrack, SHERPA.

- Building Access

1. Acquired badge access to Bldg. 481,490 .

2. Access for Bldg. 581 is pending.

\section{- Training}

1. PS 9001 - Start Orientation

2. SC9560 - Initial Security Briefing/New Employee Program

3. NP0114 - NIF Electrical Safety Awareness and Lockout/Tagout

4. IS0001-W - Integrated Safety Management Orientation

5. NP0115-W - NIF Project Site Safety Program Orientation (NPSSP)

6. NP0108 - Clean Construction Protocol Level 1\&2

7. NP0116-W - Worker

- Testing

1. Observed Barry Cline/Rob Hartley perform OSP testing.

2. Introduction and familiarization with the Video System by Barry Cline/Raelyn Clark/Ron Claybourn.

FOCUS for June 2002

- ISP Online Test Procedure for Binary Devices.

- Assignments in Bldg. 581 TBD. 


\section{Monthly Status - June 2002}

\section{Anthony J. Wilson}

\section{ACCOMPLISHMENTS}

- Continued introduction and familiarization of the Video System with Ron Claybourn.

- Performed preliminary testing of Video System with Yonas Nega against the test Matrix for all aspects that did not require ATM or Triggers/Timing functionality in the B-490 test bed.

- Completed the necessary Web Base and CBT classes to gain access to B-381, Rm. 1556.

- HS5245 Lockout and Tag

- HS5200 Laser Safety

- HS5230 High Voltage Safety In Research

o HS5210 Capacitor Safety Orientation

- HS5220 Electrical Safety Awareness

- Reviewed Introduction to Lasers and Laser Technology videos provided by the Laboratory Training Center (at home).

\section{ISSUES, IMPACTS, AND CORRECTIVE ACTIONS}

- It was decided that Video System testing would be moved to B-381, Rm. 1556 because of potential conflicts with the Power Conditioning testing in B-490 test bed.

\section{Plans for Next Period}

- Complete all aspects of the Video System testing.

- Any other TBD assignments. 


\section{Monthly Status - July}

\section{Anthony J. Wilson}

\section{ACCOMPLiShMENTS}

- Received assistance from Barry with moving and setup of Sun workstation into B381, Rm. 1556.

- Received assistance from James McBride on constructing a portable test box with three Cohu cameras and a light source mounted inside.

- Closed out the NEL1.6.4 testing and summarized results in a QLR.

- Began NEL2.2.0 Online testing in B581.

- Successful stress test for the video system. Was able to capture video images and display them simultaneously on multiple workstations for the cameras in the Hartmann Sensor FEP, ISP, OSP, and CSF.

- Worked with Ron Claybourn and Jim McBride to reproduce and investigate the "Checkered black/white patterns" that were seen from Video images in B581.

\section{ISSUES, IMPACTS, AND CORRECTIVE ACTIONS}

- NEL1.6.4 testing progress was slightly delayed partially due to a local timing system problem in B-381 Rm. 1556. I needed to wait for Barry to have time from his other priorities to assist with this problem.

- Ron Claybourn needed to borrow the ATM card from the VFEP to investigate problems in B-581.

- We were unsuccessful in identifying the root cause of the "Checkered black/white patterns" that were seen from Video still images in B581. The good news is that this problem has not been observed in B-581 since 7/30/2002.

\section{Plans for NeXt Period}

Close out all assignments and transition all information to another team member. 


\section{Quick Look Report - Video System Offline Test}

Name of Test: Video System Offline Test

Date(s) Conducted: $6 / 02-7 / 02$

Places(s) Conducted: B490 Testbed and B381, Rm 1556.

Test Procedure Number: N/A

Tester(s): Anthony J. Wilson, Yonas Nega

Developer(s): Lewis Van Atta, Ron Claybourn

Software Deployment: NEL1.6.3 and NEL1.6.4

Products Integrated and Tested:

- Video System

New Functionality Delivered:

- None.

Primary Devices/Functions/Features Tested:

- Video FEP

- Cohu Cameras

- GUI Requirements:

- Acquire Still Image

- Start/Stop Motion

- Multiple Workstations

- Network Type:

- Ethernet

- Corba

- Mode Type:

- Continuous

- Triggered

Performance Requirements Addressed:

- Multicasting Still/Triggered Still Images

- Multicasting Motion/Triggered Motion Video

\section{Summary of Test Results:}

- The general look/feel and general functionality of the Video GUI works as expected.

- It was known going into the testing that the ATM functionality was not implemented. One TI was written to cover this broad functionality.

- The major system failures that were observed were centered on continuous motion functionality. These problems were noted in the following Test Incidents: 


\section{Summary of Test Incidents:}

\begin{tabular}{|c|c|c|c|c|}
\hline TI\# & SCR\# & Priority & Description & Status \\
\hline 1489 & 2305 & Importa & $\begin{array}{l}\text { Currently all functionality for the video } \\
\text { system that requires ATM is not available. } \\
\text { Test conducted in B490; NEL1.6.3. }\end{array}$ & Assigned \\
\hline 1490 & 2307 & Normal & $\begin{array}{l}\text { There is no change that can be observed } \\
\text { when the menu item "Update", at the top of } \\
\text { the video GUI, is selected. } \\
\text { Test Conducted in B490; Release NEL1 } 6.3 \text {. }\end{array}$ & Assigned \\
\hline 1491 & 2309 & Urgent & $\begin{array}{l}\text { All test cases that cover Corba continuous } \\
\text { motion and Corba triggered motion fail. In } \\
\text { each case an error message is returned that } \\
\text { states: "Please select Ethernet or ATM } \\
\text { mode". } \\
\text { Test conducted in B490; NEL1.6.3. }\end{array}$ & Assigned \\
\hline 1495 & 2311 & $\begin{array}{l}\text { Importa } \\
\underline{\text { nt }}\end{array}$ & $\begin{array}{l}\text { Test cases that cover Ethernet Multi- } \\
\text { workstation continuous and triggered } \\
\text { motion fail. } \\
\text { Case with } 1 \text { camera image displayed on } 2 \\
\text { stations: The image on station } 1 \text { will } \\
\text { operate ok until the user attempts to start an } \\
\text { image on station } 2 \text { for the same camera. } \\
\text { This will cause the image on station } 1 \text { to } \\
\text { stop and station } 2 \text { never displays a motion } \\
\text { image. Occasionally, I have observed that } \\
\text { when the GUI on station } 2 \text { is dismissed that } \\
\text { motion will return to the image displayed on } \\
\text { station } 1 . \\
\text { Case with } 2 \text { camera images displayed on } 2 \\
\text { stations: Both images will be displayed at } \\
\text { half frames, and when the user selects stop } \\
\text { motion on station } 2 \text { GUI this will cause both } \\
\text { images of camera } 1 \text { on station } 1 \text { to stop and } \\
\text { camera } 2 \text { on station } 2 \text { to stop. } \\
\text { Test conducted in B490; NEL1.6.3. }\end{array}$ & Withdrawn \\
\hline
\end{tabular}

LLNL 


\section{COLLEGE COURSE/WORK ENHANCEMENT}

\section{IMPACT OF PREVIOUS COURSES ON WORK ASSIGNMENT}

Since the NIF ICCS software runs on Sun Microsystems workstations that run Solaris

2.8 , and Solaris is just a specific brand of Unix Operating system, I found it fairly painless to become comfortable with the control system computers. I have had previous exposure to Sun Solaris through my employment with both Scientific Atlanta, Inc. and Motorola. I have also taken Unix classes that were specific for SCO Unix, Sun Solaris, and a class that covered the File System Architecture of Red Hat Linux.

\section{IMPACT OF WORK ASSIGNMENT ON FUTURE COURSES} While the VFEP runs on a Solaris machine, some of the other FEPs, like the Alignment Controls FEP (AC FEP), operate on a VxWorks machine. VxWorks is a Real Time Operating System (RTOS) that is developed by Wind River Systems, Inc. It is one of the most widely adopted RTOS in industry. I intend on taking an Advanced Operating Systems course next spring semester. This exposure to the application of the VxWorks RTOS will enhance my knowledge and help me to understand operating systems outside the theoretical classroom setting. I have also scheduled some evening tutorial sessions with the LLNL Software Training Center to review the Rational Suite of tools that contains Rational Rose. Rational Rose is a Unified Modeling Language (UML) that provides the software developer with a complete set of visual modeling tools for modeling application logic. Understanding the lessons that will be presented in the Rational Rose tutorials will prepare me for the lessons of the Object Oriented Programming and the Software Engineering courses that I will take in my up coming semesters. 


\section{Personal Summary}

To sum up my summer work experience using only one descriptive word, I would have to say, Fantastic! LLNL is a world-renowned research laboratory that has been directly responsible for many major contributions to the U.S. scientific and technological community. I am truly thrilled to have this opportunity to work in this environment and to learn from the members of my team. The many rewards that I am receiving from working here at LLNL truly surpass any that I could be offered if I were employed by some U.S. corporate entity. From my observations, I can say that the culture and environment of the laboratory is one that believes in investing in the well being of its employees. The laboratory makes it known that continued education opportunities are abundantly available for those employees who are interested. Many science and technology seminars and symposiums are offered covering a variety of topics on a monthly basis. Many managers encourage their employees to be innovative with their approach to performing their jobs, and to move into new areas that interest them.

I am thoroughly enjoying all of the many opportunities that my summer work experience is providing. Learning about advanced laser technology and the architecture of the hardware and software systems that control these lasers has been especially rewarding for me. I would recommend to other students, undergraduate and graduate, to compliment their degree programs with some form of relevant work experience through a co-op program. Specifically, I would recommend to other students to pursue opportunities at LLNL because I think the laboratory offers a perfect mixture of advanced technology research and practical application, which would expose future engineers and scientist to areas that may not be accessible to them in corporate America. I knew that working for
LLNL
Summer Employment Summary
Page 20 of 21 
LLNL this summer would be a great opportunity for me, but I did not expect the experience to exceed my expectations to the level that it has. I am very impressed with the laboratory and the people that make it a tribute to our nation. 